\title{
Dapagliflozin: an evidence-based review of its potential in the treatment of type- 2 diabetes
}

This article was published in the following Dove Press journal:

Core Evidence

3I May 2012

Number of times this article has been viewed

\section{Edward C Chao}

University of California, San Diego and VA San Diego Healthcare System, San Diego, CA, USA
Correspondence: Edward C Chao University of California, San Diego and VA San Diego Healthcare System, 3350 La Jolla Village Drive, San Diego,

Tel +l 8585528585

Email ecchao@ucsd.edu CA 92161 , USA

Abstract: Dapagliflozin is a sodium-glucose co-transporter-2 inhibitor that lowers plasma glucose by decreasing its renal reabsorption. The resulting excretion of glucose in the urine (glucosuria) has transformed what was once solely regarded as an adverse facet of diabetes into a potential novel therapeutic strategy. Glucosuria leads to weight loss, due to a reduction in calories, which is thought to rehabilitate insulin sensitivity, at least partially. By acting independently of insulin action or secretion, dapagliflozin appears to avert or minimize two key barriers to optimal glycemic control: hypoglycemia and weight gain. From the clinical studies conducted thus far in patients with type 2 diabetes, dapagliflozin significantly decreases $\mathrm{HbA}_{1 \mathrm{c}}$ (by $\sim 0.5 \%-1 \%$, from a baseline of $8 \%-9 \%$ ), as well as body weight $(\sim 2-3 \mathrm{~kg}$ ), without increased risk of hypoglycemia. Dapagliflozin thus represents a paradigm shift in the treatment of diabetes. While long-term data on safety and efficacy are forthcoming, the results published to date suggest that this agent has the potential to be another option in the treatment of diabetes treatments. This article examines the evidence currently available on the efficacy and safety of dapagliflozin.

Keywords: dapagliflozin, SGLT2 inhibitors, type 2 diabetes mellitus, kidney

Core evidence clinical impact summary for dapagliflozin in the treatment of type-2 diabetes

\begin{tabular}{|c|c|c|}
\hline $\begin{array}{l}\text { Outcome } \\
\text { measure }\end{array}$ & Evidence & Implications \\
\hline $\begin{array}{l}\text { Disease- } \\
\text { oriented } \\
\text { evidence }\end{array}$ & $\begin{array}{l}\text { Lowers measures such as } \mathrm{HbA}_{\mathrm{lc}} \text {, fasting } \\
\text { glucose, and postprandial glucose, via a } \\
\text { novel mechanism - inhibition of renal } \\
\text { glucose reabsorption }\end{array}$ & $\begin{array}{l}\text { Weight loss without the potential for } \\
\text { hypoglycemia, which could result in } \\
\text { improved glycemic control without } \\
\text { limiting adverse effects. } \\
\text { Possible greater patient acceptance due } \\
\text { to being a PO agent }\end{array}$ \\
\hline $\begin{array}{l}\text { Patient- } \\
\text { oriented } \\
\text { evidence }\end{array}$ & $\begin{array}{l}\text { Awaiting long-term studies. Citing } \\
\text { increased numbers of cases of } \\
\text { bladder and breast cancer in patients } \\
\text { administered dapagliflozin compared } \\
\text { with control subjects, the US Food and } \\
\text { Drug Administration (FDA) recently } \\
\text { decided against approving this agent }\end{array}$ & $\begin{array}{l}\text { Unclear at present; potential adverse } \\
\text { effects, such as fungal genital infections } \\
\text { and UTI, may affect patient and provider } \\
\text { acceptance. Whether dapagliflozin is } \\
\text { associated with the cancers that have } \\
\text { raised concern is uncertain }\end{array}$ \\
\hline $\begin{array}{l}\text { Economic } \\
\text { evidence }\end{array}$ & None available yet & Currently unknown \\
\hline
\end{tabular}

\section{Introduction}

Although eleven distinct classes of diabetes medications are currently available, approximately two-thirds of patients with diabetes are not meeting their glycemic goals. ${ }^{1}$ 
The number of individuals with diabetes mellitus continues to escalate at epidemic rates. According to the International Diabetes Federation's latest estimates in 2011, 366.2 million persons worldwide have diabetes; with three new cases diagnosed around the world every ten seconds, this figure is projected to soar by $51 \%$ by $2030 .{ }^{2}$ In the USA, 25.8 million individuals are presently living with diabetes. ${ }^{3}$

Varying degrees of relative insulin deficiency and insulin resistance comprise the central defects in patients with type 2 diabetes (T2DM). Excessive gluconeogenesis by the liver, along with diminished glucose uptake by target tissues, lead to fasting and postprandial hyperglycemia. This chronic hyperglycemia can facilitate $\beta$-cell failure in the pancreas and worsen insulin resistance, thus triggering a cycle of impaired metabolism and glucose toxicity that defines diabetes. ${ }^{4}$

Aside from multiple pathophysiological defects, other factors that impede efforts to attain glycemic goals include adverse effects of the currently available agents for T2DM. For instance, metformin can cause gastrointestinal effects, such as diarrhea and nausea, and, rarely, lactic acidosis; insulin or sulfonylureas may produce hypoglycemia, as well as weight gain; and thiazolidinedione use is also associated with weight gain and edema. ${ }^{5}$ The incretin mimetics may cause nausea, vomiting, and diarrhea. ${ }^{6}$ As most current diabetes agents address insulin secretion or insulin action, with time, as the disease progresses, endogenous insulin production becomes insufficient. Exogenous insulin or another medication, if added, could result in further unwanted adverse effects. Consequently, the quest to develop novel therapeutic agents, without these side effects, continues.

The investigations carried out thus far on sodium-glucose co-transporter-2 (SGLT2) inhibitors have elucidated new perspectives not only on the mechanism of diabetes, but also on potential therapeutic applications of this knowledge. Historically, glucosuria - glucose excretion in the urine - has been viewed as a marker of metabolic decompensation and an adverse clinical consequence in the natural history of diabetes. The kidney plays a pivotal role in glucose homeostasis by regulating the reabsorption of glucose back into the plasma after filtration of the blood. In individuals with diabetes, what was once an adaptive process becomes damaging, as glucose reabsorption may increase up to $20 \%$ and perpetuate continued elevation in serum glucose levels. Blocking this process and, thus, facilitating glucose to be excreted in the urine, is being examined as a potential new therapeutic target in diabetes. Thus, effecting glycosuria for treating diabetes is a paradigm shift. As SGLT2 inhibitors target the renal handling of glucose and would not be expected to cause hypoglycemia - thus, acting independently of insulin resistance and insulin secretion - they represent potentially promising novel agents in the treatment of diabetes.

By decreasing renal glucose reabsorption due to enhancing urinary glucose excretion, SGLT2 inhibitors decrease the hyperglycemia that contributes to insulin resistance and diminished insulin secretion. Blockade of SGLT2 also appears to ameliorate pathophysiological defects underlying T2DM other than hyperglycemia, including factors such as weight gain, blood pressure, and lipids. This article provides a brief overview of the history of the development and the mechanism of the action of SGLT2 inhibitors, and it will focus on clinical studies of dapagliflozin.

\section{Renal glucose handling and SGLT}

The role of the kidney in glucose balance has been insufficiently appreciated; however, it is no less crucial. Together with the liver, the kidney provides glucose during periods of fasting. The kidney not only contributes to gluconeogenesis (approximately $15-55 \mathrm{~g}$ per day, or $20 \%-25 \%$ of the glucose released into the circulation after an overnight fast), but also reabsorbs glucose (Figure 1). ${ }^{7}$

In individuals without diabetes, in the setting of a plasma glucose concentration of $\sim 90 \mathrm{mg} / \mathrm{dL}$, essentially

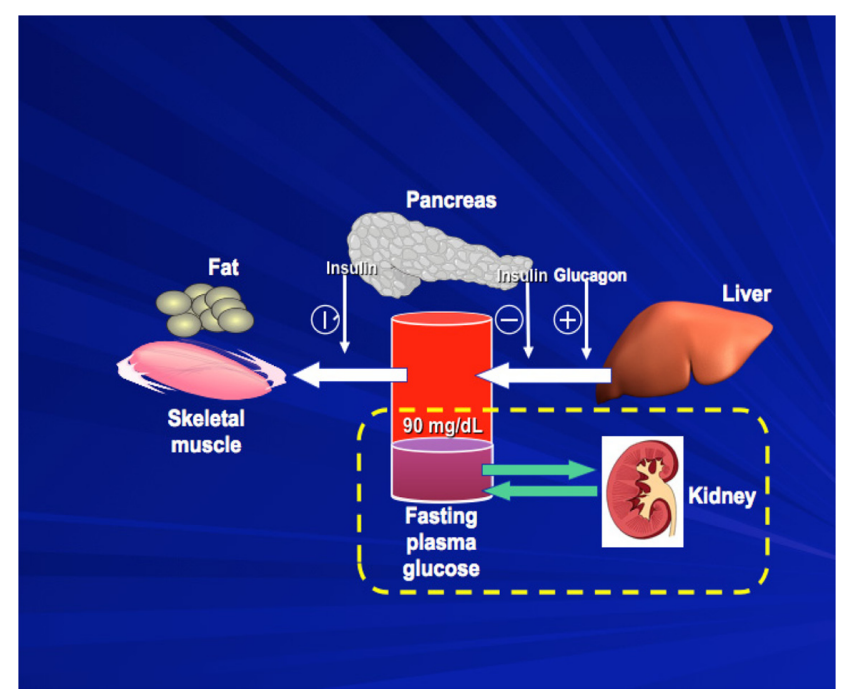

Figure I Normal glucose homeostasis.

Notes: This figure depicts the hormonal interactions that are key in normal glucose homeostasis. Normal fasting glucose homeostasis involves the regulation of glucose utilization and production, as well as the filtration and reabsorption of glucose by the kidney. Under basal conditions, glucose uptake by the tissues is matched by glucose production from the liver, which enables precise regulation of glucose at a very fixed level. Copyright (C) 2010, Nature Pub. Group. Adapted from DeFronzo RA. Pharmacologic therapy for type 2 diabetes mellitus. Ann Intern Med. 1999;|3I(4):28I-303. ${ }^{34}$ Reproduced with permission from Chao EC, Henry RR. SGLT2 inhibition - a novel strategy for diabetes treatment. Nat Rev Drug Discovery. 2010;9(7):55I-559. ${ }^{8}$ 
all of the $\sim 180 \mathrm{~g}$ of glucose that is filtered per day by the glomeruli is reabsorbed. ${ }^{9}$ Sodium-glucose co-transporters (SGLTs) are the specific mediators of renal glucose reabsorption, with $90 \%$ of this reabsorption being facilitated by the isoform termed SGLT2, and the remainder by SGLT1 (Figure 2). Found mainly in the S1 segment of the proximal convoluted tubule (PCT) of the kidney, SGLT2 is expressed almost entirely in the kidney; it is a high-capacity, low-affinity transporter. ${ }^{10}$ Both expression and function of SGLT2 are increased in patients with T2DM. ${ }^{11}$ SGLT1 is a low-capacity, high-affinity co-transporter located more distally, in the PCT's S2 and S3 segments. ${ }^{10}$

As this filtrate passes through the proximal tubule of the kidney, SGLT2 transporters located on the luminal surface combine active transport of glucose (against a concentration gradient) with that of sodium (Figure 3). ${ }^{12}$ Glucose transporters (specifically, GLUT2) carry glucose into the basolateral aspect, or the blood, by passive transport (with a concentration gradient).

As glucose increases, reabsorption by the kidney continues, without any glucose being excreted, until a theoretical threshold is reached (approximately $11 \mathrm{mmol} / \mathrm{L}$ or $200 \mathrm{mg} / \mathrm{dL}$ ) (Figure 4). ${ }^{13}$ As this threshold is approached, the SGLTs reach saturation; once exceeded, glucose begins to appear in the urine. The actual threshold is somewhat lower, due to both anatomical and physiological variations among individual nephrons, such as the observation that not all nephrons exhibit the same threshold for reabsorption

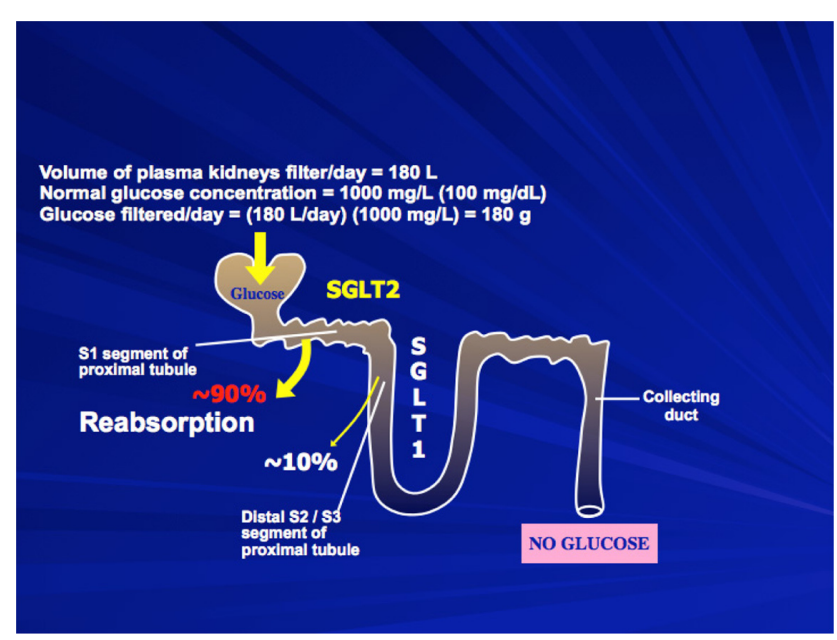

Figure 2 Glucose regulation by the kidneys in a non-diabetic individual. Copyright (c) Nature Pub. Group. Adapted from Wright EM. Renal $\mathrm{Na}(+)$-glucose cotransporters. Am J Physiol Renal Physiol. 200I;280(I):FI0-FI8. ${ }^{35}$ Reproduced with permission from Chao EC, Henry RR. SGLT2 inhibition - a novel strategy for diabetes treatment. Nat Rev Drug Discovery. 2010;9(7):55I-559. ${ }^{8}$

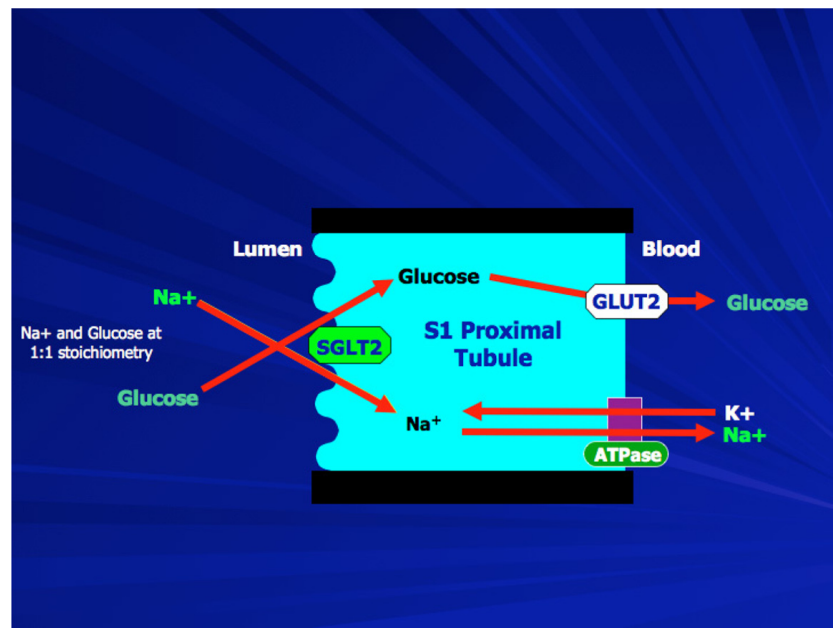

Figure 3 SGLT2 mediates glucose reabsorption in the kidney and catalyzes the active transport of glucose (against a concentration gradient) across the luminal membrane, by coupling it with the downhill transport of $\mathrm{Na}^{+}$.

Notes: The inward $\mathrm{Na}^{+}$gradient across the luminal epithelium is maintained by active extrusion of $\mathrm{Na}^{+}$across the basolateral surface into the intercellular fluid, which is in equilibrium with the blood. Glucose passively diffuses out of the cell, down a concentration gradient, via basolateral facilitative transporters, GLUT2 (and GLUTI) Copyright (C) 2010, Nature Pub. Group.

Reproduced with permission from Chao EC, Henry RR. SGLT2 inhibition - a novel strategy for diabetes treatment. Nat Rev Drug Discovery. 20 10;9(7):55I-559. ${ }^{8}$

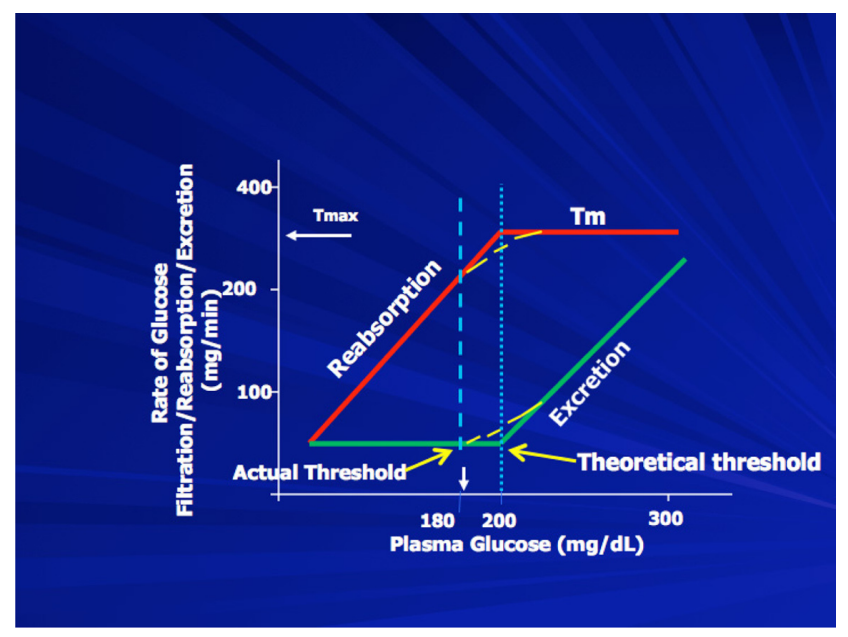

Figure 4 Renal glucose handling before and following inhibition of SGLT2.

Notes: With gradual infusion of glucose, as the plasma glucose concentration increases, the reabsorption progressively increases, following the line marked "Reabsorption" (in red). At plasma glucose concentrations $<200 \mathrm{mg} / \mathrm{dL}$, all the filtered glucose is reabsorbed, and there is no excretion. When glucose reaches a threshold, at $\sim 200-250 \mathrm{mg} / \mathrm{dL}$, the maximum capacity of the renal tubule to reabsorb glucose - the $T_{\max }$ - is exceeded. Once past this threshold, glucose begins to be excreted into the urine (green line, labeled "Excretion"). The breaking point, however, is not abrupt. Splay, which represents glucose excretion in the urine before saturation $\left(T_{\max }\right)$, is fully attained and is explained by some nephrons releasing glucose at a slightly lower threshold (some a bit higher) and the relatively low affinity of the Na-glucose carriers. The dotted yellow lines depict renal glucose handling after SGLT2 inhibition. The SGLT2 inhibitors lower the $T_{\max }$ of glucose, which in turn increases the excretion of glucose via the kidneys. Copyright (C) 2010, Nature Pub. Group.

Reproduced with permission from Chao EC, Henry RR. SGLT2 inhibition - a novel strategy for diabetes treatment. Nat Rev Drug Discovery. 2010;9(7):55I-559. ${ }^{8}$ 
and excretion. This difference between the theoretical and actual thresholds is termed "splay," and it is depicted as the curvilinear slope for both the reabsorption and excretion curves. Inhibition of SGLT is due to lowering of the $\mathrm{T}_{\mathrm{mG}}$, or decreasing the excretion threshold, or both.

\section{Familial renal glucosuria}

Mutations in the gene encoding SGLT2 result in an autosomal genetic disorder, familial renal glucosuria (FRG). The transmission of this rare disease is thought to be co-dominant with incomplete penetrance. Patients have excreted as much as $170 \mathrm{~g}$ of glucose per day, are asymptomatic, and have no known abnormalities of glucose or renal function; have not demonstrated an increased incidence of diabetes, chronic kidney disease, or urinary tract infection; and have normal life expectancy. ${ }^{14}$ Some have suggested that FRG serves as a model for SGLT2 inhibition. The two may not be completely similar, as there are immunity abnormalities that are found in T2DM patients, but not in those with FRG. Such impaired immunity may explain the potential for increased urinary tract and genital fungal infections in patients with T2DM (discussed later in this review).

\section{Development of early SGLT inhibitors - phlorizin}

The Greek physician Aretaeus of Cappadocia, in the second century $\mathrm{AD}$, suggested that diabetes was due to a derangement in the kidneys, and he postulated that polyuria was a compensatory mechanism. ${ }^{15}$ The kidney's role in glucose homeostasis had been less recognized until relatively recently. In 1835, phlorizin was isolated from the root bark of the apple tree by French chemists. ${ }^{16}$ In a landmark study, phlorizin was demonstrated to reverse insulin resistance and beta-cell dysfunction. ${ }^{17}$ Diabetes was induced in rats that had undergone partial pancreatectomies. Phlorizin administration increased urinary glucose excretion, normalized both fasting and postprandial plasma glucose, and completely reversed glucotoxicity. Once phlorizin was discontinued, diabetes and its markers were restored. This and subsequent investigations established the concept that hyperglycemia contributes to insulin resistance and, thus, to the development of diabetes.

Phlorizin could not be used clinically, as its O-glycoside linkage rendered it susceptible to rapid degradation, and thus, low bioavailability. ${ }^{16}$ This compound also was a nonselective SGLT inhibitor; that is, it blocked both SGLT1 and SGLT2. SGLT1, predominantly expressed in the small intestine and other regions, such as the kidney, transports both glucose and galactose. Diminished absorption of glucose and galactose leads to potentially severe dehydration and diarrhea. ${ }^{16}$ Phloretin is a breakdown product of phlorizin, and it inhibits multiple GLUTs, with the consequence of impairment of glucose transport.

Dapagliflozin (BMS-512148; AstraZeneca, BristolMyers Squibb) is the SGLT2 inhibitor that has progressed the furthest in development. This agent has a C-glycoside linkage that confers greater stability than its predecessor compounds, allowing once-daily dosing. The half-life is approximately 17 hours, and maximal plasma concentration is reached in about two hours. ${ }^{18}$ Dapagliflozin is 1200 -fold more specific for SGLT2 than for SGLT1. ${ }^{19}$

\section{Improved plasma glucose and $\mathrm{HbA}_{\mathrm{Ic}}$}

Dapagliflozin has been shown, in multiple clinical studies, to reduce both $\mathrm{HbA}_{1 \mathrm{c}}$ and fasting plasma glucose. Subjects with T2DM exhibited blockade of glucose reabsorption that was dose-dependent for 5, 25, and $100 \mathrm{mg}$ of dapagliflozin, which ranged from $20 \%$ to $44 \%$ over 14 days; glucosuria was observed to be up to $70 \mathrm{~g} /$ day, which is equivalent to approximately $280 \mathrm{cal} .{ }^{18}$ Patients with diabetes uncontrolled with oral diabetes agents for six weeks or more - metformin $\geq 1,000 \mathrm{mg}$ and/or pioglitazone $\geq 30 \mathrm{mg}$ or rosiglitazone $4 \mathrm{mg}$ - and on at least 12 weeks of insulin and at least 6 weeks of a stable insulin dose at $\geq 50$ units daily demonstrated mean changes in $\mathrm{HbA}_{1 \mathrm{c}}$ of $-0.70 \%$ for dapagliflozin $10 \mathrm{mg}$ and $-0.78 \%$ for dapagliflozin $20 \mathrm{mg}$ at twelve weeks. ${ }^{20}$

Dapagliflozin administration led to significant placeboadjusted reductions in $\mathrm{HbA}_{1 \mathrm{c}}$ of $-0.58 \%,-0.77 \%$, and $-0.89 \%$ in 485 newly diagnosed, treatment-naïve T2DM patients controlled by diet and exercise administered 2.5, 5, and $10 \mathrm{mg}$ of dapagliflozin, respectively. The $\mathrm{HbA}_{1 \mathrm{c}}$ change in the placebo group was $-0.23 \% .{ }^{21}$ Dapagliflozin 5 and $10 \mathrm{mg}$ daily administered to a subgroup of 74 subjects with $\mathrm{HbA}_{1 \mathrm{c}}$ between $10.1 \%$ and $12.0 \%$ lowered this measure by $2.88 \%$ and $2.66 \%$, respectively. When added to metformin, $\mathrm{HbA}_{1 \mathrm{c}}$ decreased $-0.54 \%$ in subjects on dapagliflozin. The first large clinical trial of dapagliflozin examined 534 patients with T2DM, inadequately controlled on metformin. ${ }^{21}$ At week 24, dapagliflozin in doses of $2.5,5$, and $10 \mathrm{mg}$ per day yielded a decline in the mean $\mathrm{HbA}_{1 \mathrm{c}}$ of $-0.67 \%,-0.70 \%$, and $-0.84 \%$; the reduction was $-0.30 \%$ in the placebo group. A 24-week trial of 597 patients with T2DM uncontrolled on sulfonylurea monotherapy revealed decreases in $\mathrm{HbA}_{1 \mathrm{c}}$ across all dose groups; placebo: $-0.13 \%$; $2.5 \mathrm{mg}$ : $-0.58 \%$; $5 \mathrm{mg}$ : $-0.63 \%$; and $10 \mathrm{mg}:-0.82 \% .{ }^{23}$ Dapagliflozin was demonstrated to be noninferior to glipizide, as an add-on agent to metformin; 
both groups' $\mathrm{HbA}_{1 \mathrm{c}}$ declined by $-0.52 \%$ at 52 weeks. ${ }^{24}$ What was notable was the path taken - the glipizide + metformin group declined more sharply, but it gradually increased during the maintenance period. The dapagliflozin + metformin cohort experienced a slower and less steep, though sustained, decline. A trial compared 151 subjects with diabetes of one year duration (early stage) with 58 subjects with diabetes for a mean of 11.1 years (late stage). ${ }^{25}$ These patients were randomized into groups of dapagliflozin 10 or $20 \mathrm{mg}$ daily for 12 weeks. The $\mathrm{HbA}_{1 \mathrm{c}}$ in the late stage group decreased $0.5 \%-0.7 \%$, from $8.4 \%$, and the early stage cohort declined $0.6 \%-0.8 \%$, from $7.6 \%$. The similar degree of reduction in $\mathrm{HbA}_{1 \mathrm{c}}$ is due to the insulin-independent mechanism of action of dapagliflozin.

A 24-week clinical trial was the first to investigate dapagliflozin as initial monotherapy and in combination with metformin in treatment-naïve T2DM patients. ${ }^{26}$ Two randomized trials compared dapagliflozin plus metformin, dapagliflozin alone, and metformin alone. Study 1 dosed dapagliflozin at $5 \mathrm{mg}$; study 2 , at $10 \mathrm{mg}$. Significantly greater reductions in $\mathrm{HbA}_{1 \mathrm{c}}$ were seen with combination therapy compared with monotherapy in both studies: in study 1: $-2.05 \%$ for dapagliflozin + metformin; $-1.19 \%$ for dapagliflozin; and $-1.35 \%$ for metformin. Study 2 demonstrated $-1.98 \%$ for dapagliflozin + metformin, $-1.45 \%$ for dapagliflozin, and $-1.44 \%$ for metformin.

Wilding et al examined the effect of dapagliflozin on glycemic control in patients with T2DM uncontrolled on insulin, with or without oral antidiabetic medications. ${ }^{27}$ These subjects, and patients previously taking pioglitazone $\geq 30 \mathrm{mg}$, were subsequently randomized into groups of dapagliflozin $5 \mathrm{mg}$, dapagliflozin $10 \mathrm{mg}$ daily, or placebo daily, along with open-label pioglitazone. The mean decrease in $\mathrm{HbA}_{1 \mathrm{c}}$ from baseline was $-0.82 \%$ and $-0.97 \%$ for the dapagliflozin $5 \mathrm{mg}$ and $10 \mathrm{mg}$ groups, respectively. The decline in those on placebo was $-0.42 \%$.

T2DM patients who were treatment-naïve, or those on metformin, sulfonylurea, or a thiazolidinedione, were administered pioglitazone for ten weeks. ${ }^{28}$ In subjects administered dapagliflozin $2.5 \mathrm{mg}$ daily, mean $\mathrm{HbA}_{1 \mathrm{c}}$ decreased by $-0.79 \%$ to $-0.96 \%$; by $-0.49 \%$ for those on $5 \mathrm{mg}$ daily; and $-0.57 \%$ for the $10 \mathrm{mg}$ group (the reduction for the placebo cohort was $-0.39 \%$ ).

\section{Reduced total body weight}

Dapagliflozin, whether given as monotherapy or when added to other agents, has resulted in statistically significant weight loss. As monotherapy, dapagliflozin caused weight loss from -2.7 to $-3.2 \mathrm{~kg}$ at 24 weeks. ${ }^{21}$ Statistically significant, dose-dependent reductions were observed on day 13 of a two-week study of 47 patients with T2DM: $-18.8,-28.8$, and $-38.7 \mathrm{mg} / \mathrm{dL}$ for the $5 \mathrm{mg}(-11.7 \%), 25 \mathrm{mg}(-13.3 \%)$, and $100 \mathrm{mg}(-21.8 \%)$ doses, respectively, as compared with the placebo group. ${ }^{18}$ When administered along with metformin, weight loss persisted over two years: $-2.8 \mathrm{~kg}$ compared with $-0.7 \mathrm{~kg}$ for the placebo. When added to subjects who were suboptimally controlled on high doses of insulin and oral antidiabetic agents, the mean changes in total body weight were $-4.5 \mathrm{~kg}$ for those on $10 \mathrm{mg}$ of dapagliflozin and $-4.3 \mathrm{~kg}$ for those on $20 \mathrm{mg} .{ }^{20}$ The change for the placebo group was $-1.9 \mathrm{~kg}$. Bailey et al found $-0.9 \mathrm{~kg}$ for the subjects on placebo, $-2.2 \mathrm{~kg}$ for dapagliflozin $2.5 \mathrm{mg}$, $-3.0 \mathrm{~kg}$ for $5 \mathrm{mg}$, and $-2.9 \mathrm{~kg}$ for $10 \mathrm{mg} .{ }^{22}$ In the Nauck et al study, dapagliflozin led to weight loss of $-3.2 \mathrm{~kg}$ with dapagliflozin $2.5 \mathrm{mg}$ versus weight gain $(1.2 \mathrm{~kg} ; P<0.0001)$ with glipizide $5 \mathrm{mg} .{ }^{24}$ Strojek et al detected body weight reductions in the placebo, $2.5 \mathrm{mg}, 5 \mathrm{mg}$, and $10 \mathrm{mg}$ groups of $-0.72 \mathrm{~kg},-1.18 \mathrm{~kg},-1.56 \mathrm{~kg}$, and $-2.26 \mathrm{~kg}$, respectively. ${ }^{23}$ A study of 182 patients with T2DM suboptimally controlled on metformin examined the effect of dapagliflozin $10 \mathrm{mg}$ versus placebo on total body weight. At week 24 , the placebocorrected change in TBW was $-2.08 \mathrm{~kg}$ [95\% confidence interval (CI): -2.84 to $-1.31 ; P<0.0001] .{ }^{29}$ The 24 -week study comparing dapagliflozin, metformin XR, or both, as initial therapy, revealed $-2.66 \mathrm{~kg},-2.61 \mathrm{~kg},-1.29 \mathrm{~kg}$ in the dapagliflozin + metformin, dapagliflozin, and metformin groups, respectively in study 1 . Study 2 reductions were $-3.33 \mathrm{~kg},-2.73 \mathrm{~kg}$, and $-1.36 \mathrm{~kg}$, respectively. ${ }^{26}$ In the clinical trial by Wilding et al of patients on insulin, body weight decreased by -0.92 to $-1.61 \mathrm{~kg}$ with dapagliflozin and increased by $0.43 \mathrm{~kg}$ with the placebo in the $2.5 \mathrm{mg}$ group, $-1.42 \mathrm{~kg}$ in the $5 \mathrm{mg}$ group, and $-2.04 \mathrm{~kg}$ in the $10 \mathrm{mg}$ group. ${ }^{27}$ The study by Ferrannini et $\mathrm{al}^{21}$ was an exception, in that the mean body weight reductions did not reach statistical significance, although they were higher than with the placebo at all doses. The subjects in this study were treatment-naïve, and their hyperglycemia was not controlled by lifestyle-only changes, which is a key difference from most of the other clinical trials on dapagliflozin to date. The Zhang et $\mathrm{al}^{25}$ and Henry et $\mathrm{al}^{26}$ studies are exceptions.

\section{Reduced fasting glucose}

Dose-dependent decreases in fasting plasma glucose (FPG) have been observed. Mean changes in FPG from baseline FPG were $-18.8,-28.8$, and $-38.7 \mathrm{mg} / \mathrm{dL}$ in the $5 \mathrm{mg}, 25 \mathrm{mg}$, and $100 \mathrm{mg}$ dose groups, respectively. In another study, they 
were $+17.8,+2.4$, and $-9.6 \mathrm{mg} / \mathrm{dL}$ (placebo, $10 \mathrm{mg}$ dapagliflozin, and $20 \mathrm{mg}$ dapagliflozin, respectively). ${ }^{20}$ Ferrannini et al found FPG reductions of $-15.2,-24.1,-28.8$, and $-4.1 \mathrm{mg} / \mathrm{dL}$ for doses of $2.5 \mathrm{mg}, 5 \mathrm{mg}, 10 \mathrm{mg}$, and placebo, respectively. ${ }^{21} \mathrm{In}$ the study by Strojek et al, FPG decreased by $-2.0,-16.8,-21.3$, and $-28.5 \mathrm{mg} / \mathrm{dL}$ in the placebo and dapagliflozin $2.5 \mathrm{mg}$, $5 \mathrm{mg}$, and $10 \mathrm{mg}$ dose groups, respectively. ${ }^{23}$ FPG was not a primary or secondary endpoint for the Nauck et al trial. ${ }^{24}$ In the Henry et al study 1 cohort, FPG decreased by $-61.1,-42.0$, $-33.5 \mathrm{mg} / \mathrm{dL}$ in the dapagliflozin + metformin, dapagliflozin, and metformin groups, respectively. In study 2 , the reductions in FPG were $-60.4,-46.5$, and $-34.8 \mathrm{mg} / \mathrm{dL}$, respectively. ${ }^{26}$

\section{Effect on fat mass and regional adipose tissue distribution}

Bolinder et al also examined the secondary endpoints of waist circumference, which decreased $-1.52 \mathrm{~cm} .{ }^{29}$ Fat mass declined $-1.48 \mathrm{~kg}$; the visceral adipose tissue (VAT) decreased $-258.4 \mathrm{~cm}^{3}$, and the subcutaneous adipose tissue (SAT) reduced by $184.9 \mathrm{~cm}^{3}$.

\section{Safety}

While no long-term data on adverse effects with dapagliflozin have yet been published, adverse events were generally balanced across treatment groups and were usually minor. No severe hypoglycemic events have been observed thus far; the small number of instances of hypoglycemia noted were self-limiting and mild. ${ }^{20-24}$ Glucosuria can potentially result in increased risk of genital fungal and urinary tract infections. Vulvovaginal infections in females and balanitis in males have occurred in increased numbers in subjects on dapagliflozin $(\sim 8 \%-10 \%)$ compared with those on placebo $(\sim 3 \%-5 \%)$. $^{20-22}$ Most of these infections were mild to moderate in intensity, and they either responded to medication or spontaneously resolved; a number of these infections were self-reported and could not be confirmed by microbiological culture testing. These adverse events rarely led to discontinuation of dapagliflozin. Various clinical trials have noted a slight increase in the rate of UTI, up to $13 \%$ of subjects with T2DM who were treatment-naïve or who were suboptimally controlled on metformin, compared with $1.3 \%$ and $5 \%$ in those two groups, respectively. ${ }^{21,22,24}$

Systolic blood pressure declined by $3-5 \mathrm{mmHg}$ and diastolic blood pressure by $\sim 2 \mathrm{mmHg}$ with $10 \mathrm{mg} /$ day dose of dapagliflozin. ${ }^{21,22}$ These reductions are in accord with the diuretic effect of this agent, and they were unaccompanied by greater instances of orthostatic hypotension. Data thus far have not shown an increased risk of cardiovascular disease.
As both glucose and sodium are co-transported, and thus are both inhibited, dapagliflozin may cause an elevation in urinary excretion of sodium. Although such transient increases in urine sodium have been reported, there have been no clinically significant changes in serum sodium. ${ }^{18}$ Studies have documented slight increases in serum magnesium, phosphorus, hematocrit, and blood urea nitrogen (BUN). ${ }^{22,24}$ The elevated hematocrit is also consistent with the diuresis that is a property of dapagliflozin. Serum creatinine did not change. Small declines in serum uric acid and high-sensitivity $\mathrm{C}$-reactive protein have been seen. ${ }^{30}$ The implications of such findings are not yet certain; for instance, there is an association with increased serum uric acid and DM, renal dysfunction, and cardiovascular disease, although no etiologic link has been established. ${ }^{31,32}$

By a vote of nine to six, on July 19, 2011, an FDA advisory committee recommended against approval of dapagliflozin. ${ }^{33}$ The panel cited concerns over reported cases of bladder cancer and breast cancer, as well as potential effects on the liver. Out of 4310 individuals who were administered dapagliflozin, nine total cases of bladder cancer were detected, while one of 1962 subjects had bladder cancer in the control group. (Two of the nine cases of bladder cancer in the dapagliflozin group and the one in the control group were reported after the 4-month Safety Update cutoff date.) Before randomization, three subjects on dapagliflozin had microscopic hematuria, and one had trace hematuria.

Nine of 4287 patients in the dapagliflozin group were reported to have breast cancer; none of 1941 placebo subjects were found to have this cancer. Subjects were on dapagliflozin for a shorter duration ( $<1$ year) than the average of more than 5 years suggested as sufficient for the detection of breast cancer.

Of five patients taking dapagliflozin who met the criteria for Hy's Law (defined as an aspartate aminotransferase [AST] or alanine transaminase [ALT] greater than three times the upper limit of normal, and an increase in total bilirubin greater than two times the upper limit of normal), one was considered a "probable diagnosis of mild to moderately severe dapagliflozin-induced liver injury." 33 Two of those five subjects had transaminitis - an AST or ALT greater than three times the upper limit of normal - that may have been due to drug-induced injury. On January 19, 2012, the FDA did not approve dapagliflozin. The FDA sent Complete Response Letters to BMS and AstraZeneca, requesting "additional clinical data to allow a better assessment of the benefit-risk profile." Detection bias has been proposed as a possible explanation; for instance, for the bladder cancer cases, there may have been a higher number of urinalyses conducted in the study 
subjects. These cancer signals could indicate that neoplasms were developing before dapagliflozin treatment had begun. The number of cases does not allow one to reach conclusions about whether this agent is the cause of the hepatic and cancer events. While approval of dapagliflozin at a later date remains to be determined, it is clear that these signals raised concerns, and further studies will possibly be undertaken.

\section{Unanswered questions}

Although dapagliflozin has been studied in over 5,000 patients in 19 clinical trials, unresolved questions remain. Dapagliflozin is thought to be less effective in patients with existing compromised renal function: moderate impairment has been defined as an estimated glomerular filtration rate $\geq 30$ and $<60 \mathrm{~mL} / \mathrm{min}$. These subjects had the greatest number of adverse events of renal impairment or renal failure. How this agent would impact renal function in the long term is uncertain. Would patients and their physicians be hesitant to start a medication with the potential for fungal infections and UTI?

The literature, to date, suggests that dapagliflozin could serve as either monotherapy or as an add-on to metformin, sulfonylureas, and insulin. Dapagliflozin's place in the treatment of diabetes remains to be clarified. Studies have been conducted only in patients with type 2 diabetes; effects on those with type 1 diabetes are unknown.

Dapagliflozin causes increased urinary glucose excretion, which leads to weight loss. Whether this reduction is attributable to fluid loss secondary to osmotic diuresis, or to decreased body fat due to a deficit in calories, or both, has been unclear. The study by Bolinder et al revealed that dapagliflozin significantly lowered both DEXA fat mass and total body weight. ${ }^{29}$ Approximately two-thirds of the weight decline with dapagliflozin subjects was due to fat mass reduction, compared with half of such a loss with those randomized to placebo. ${ }^{25}$ These findings were associated with sustained elevations in urinary glucose excretion, thus lending support to caloric deficit as the main source of weight loss. The initial rapid decline in TBW may have been largely a result of fluid loss. The issue can still be considered unresolved, as spot urinary glucose excretion, and not 24-hour excretion, was measured in this study; in addition, food and fluid intake were not controlled.

How the FDA's decision could impact the development of this class is uncertain. As dapagliflozin is a first-in-class agent, the companies developing other SGLT2 inhibitors, such as canagliflozin, may face similar concerns, and will possibly be able to anticipate the safety concerns and provide data.

\section{Conclusion}

Dapagliflozin employs a novel, insulin-independent mechanism of action to promote glucosuria and, thus, loss of calories. This weight loss is thought to ameliorate insulin resistance and consequent glucotoxicity. Therefore, while this agent and other SGLT2 inhibitors do not directly affect insulin secretion or sensitivity, the impact is indirect, due to effects on reducing hyperglycemia. While long-term efficacy and safety data are pending, and questions have been raised from the FDA's recent decision on dapagliflozin's approval status, data from studies thus far suggest a potential role for this agent. The kidney is being viewed differently than it has been traditionally, and it is thus being utilized as a potential novel target for therapy.

\section{Acknowledgments}

The VA San Diego Healthcare System and University of California, San Diego School of Medicine supported the writing of this article.

\section{Disclosure}

The author reports no conflicts of interest in this work.

\section{References}

1. Del Prato S, Felton AM, Munro N, et al. Improving glucose management: ten steps to get more patients with type 2 diabetes to glycaemic goal. Int J Clin Pract. 2005;59(11):1345-1355.

2. International Diabetes Federation. Diabetes Atlas, 5th ed. Brussels: International Diabetes Federation; 2011.

3. http://www.cdc.gov [homepage on the Internet]. Atlanta: Centers for Disease Control. 2011 National Diabetes Fact Sheet. Available from: http:// www.cdc.gov/diabetes/pubs/factsheet11.htm. Accessed April 27, 2012.

4. Prentki M, Nolan CJ. Islet beta cell failure in type 2 diabetes. J Clin Invest. 2006;116(7):1802-1812.

5. Inzucchi SE. Oral antihyperglycemic therapy for type 2 diabetes: scientific review. JAMA. 2002;287(3):360-372.

6. Buse JB, Henry RR, Han J, et al. Effects of exenatide (exendin-4) on glycemic control over 30 weeks in sulfonylurea-treated patients with type 2 diabetes. Diabetes Care. 2004;27(11):2628-2635.

7. Gerich JE. Role of the kidney in normal glucose homeostasis and in the hyperglycaemia of diabetes mellitus: therapeutic implications. Diabet Med. 2010;27(2):136-142.

8. Chao EC, Henry RR. SGLT2 inhibition - a novel strategy for diabetes treatment. Nat Rev Drug Discovery. 2010;9(7):551-559.

9. Wright EM, Hirayama BA, Loo DF. Active sugar transport in health and disease. J Intern Med. 2007;261(1):32-43.

10. Wood IS, Trayhurn P. Glucose transporters (GLUT and SGLT): expanded families of sugar transport proteins. Br J Nutr. 2003;89(1):3-9.

11. Rahmoune H, Thompson PW, Ward JM, Smith CD, Hong G, Brown J. Glucose transporters in human renal proximal tubular cells isolated from the urine of patients with non-insulin-dependent diabetes. Diabetes. 2005;54(12):3427-3434.

12. Wright EM, Turk E. The sodium/glucose cotransport family SLC5. Pflugers Arch. 2004;447(5):510-518.

13. DeFronzo RA, Davidson JA, Del Prato S. The role of the kidneys in glucose homeostasis: a new path towards normalizing glycaemia. Diabetes Obes Metab. 2012;14(1):5-14. 
14. Santer R, Kinner M, Lassen CL, et al. Molecular analysis of the SGLT2 gene in patients with renal glucosuria. J Am Soc Nephrol. 2003; 14(11):2873-2882.

15. Krall LP, Levine R, Barnett D. The History of Diabetes. In: Kahn CR, Weir GC, editors. Joslin's Diabetes Mellitus. Philadelphia: Lea and Febiger; 1994:2.

16. Ehrenkranz JR, Lewis NG, Kahn CR, Roth J. Phlorizin: a review. Diabetes Metab Res Rev. 2005;21(1):31-38.

17. Rossetti L, Smith D, Shulman GI, Papachristou D, DeFronzo RA. Correction of hyperglycemia with phlorizin normalizes tissue sensitivity to insulin in diabetic rats. J Clin Invest. 1987;79(5):1510-1515.

18. Komoroski B, Vachharajani N, Feng Y, Li L, Kornhauser D, Pfister M. Dapagliflozin, a novel, selective SGLT2 inhibitor, improved glycemic control over 2 weeks in patients with type 2 diabetes mellitus. Clin Pharmacol Ther. 2009;85(5):513-519.

19. Han S, Hagan DL, Taylor JR, et al. Dapagliflozin, a selective SGLT2 inhibitor, improves glucose homeostasis in normal and diabetic rats. Diabetes. 2008;57(6):1723-1729.

20. Wilding JPH, Norwood P, T'joen C, Bastien A, List JF, Fiedorek FT. A study of dapagliflozin in patients with type 2 diabetes receiving high doses of insulin plus insulin sensitizers: applicability of a novel insulin-dependent treatment. Diabetes Care. 2009;32(9): 1656-1662.

21. Ferrannini E, Ramos SJ, Salsali A, Tang W, List JF. Dapagliflozin monotherapy in type 2 diabetic patients with inadequate glycemic control by diet and exercise: a randomized, double-blind, placebo-controlled, phase 3 trial. Diabetes Care. 2010;33(10):2217-2224.

22. Bailey CJ, Gross JL, Pieters A, Bastien A, List JF. Effect of dapagliflozin in patients with type 2 diabetes who have inadequate glycaemic control with metformin: a randomised, double-blind, placebo-controlled trial. Lancet. 2010;375(9733):2223-2233.

23. Strojek K, Yoon KH, Hruba V, Elze M, Langkilde AM, Parikh S. Effect of dapagliflozin in patients with type 2 diabetes who have inadequate glycaemic control with glimepiride: a randomized, 24-week, doubleblind, placebo-controlled trial. Diabetes Obes Metab. 2011;13(10): 928-938.

24. Nauck MA, Del Prato S, Meier JJ, et al. Dapagliflozin versus glipizide as add-on therapy in patients with type 2 diabetes who have inadequate glycemic control with metformin: a randomized, 52-week, doubleblind, active-controlled noninferiority trial. Diabetes Care. 2011;34(9): 2015-2022.
25. Zhang L, Feng Y, List J, Kasichayanula S, Pfister M. Dapagliflozin treatment in patients with different stages of type 2 diabetes mellitus: effects on glycaemic control and body weight. Diabetes Obes Metab. 2010;12(6):510-516.

26. Henry RR, Murray AV, Marmolejo MH, Hennicken D, Ptaszynska A, List JF. Dapagliflozin, metformin XR, or both: initial pharmacotherapy for type 2 diabetes, a randomised controlled trial. Int J Clin Pract. 2012; doi: 10.1111/j.1742-1241. Epub March 13, 2012.

27. Wilding JP, Woo V, Soler NG; for the Dapagliflozin 006 Study Group. Long-term efficacy of dapagliflozin in patients with type 2 diabetes mellitus receiving high doses of insulin: a randomized trial. Ann Intern Med. 2012;156(6):405-415

28. Rosenstock J, Vico M, Wei L, Salsali A, List JF. Effects of dapagliflozin, a sodium-glucose cotransporter-2 inhibitor, on hemoglobin A1c, body weight, and hypoglycemia risk in patients with type 2 diabetes inadequately controlled on pioglitazone monotherapy. Diabetes Care. March 23, 2012. [Epub ahead of print.]

29. Bolinder J, Ljunggren O, Kullberg J, et al. Effects of dapagliflozin on body weight, total fat mass, and regional adipose tissue distribution in patients with type 2 diabetes mellitus with inadequate glycemic control on metformin. J Clin Endocrinol Metab. 2012;97(3):1020-1031.

30. List JF, Woo V, Morales E, Tang W, Fiedorek FT. Sodium-glucose cotransport inhibition with dapagliflozin in type 2 diabetes. Diabetes Care. 2009;32(4):650-657.

31. Kodama S, Saito K, Yachi Y, et al. Association between serum uric acid and development of type 2 diabetes. Diabetes Care. 2009; 32(9):1737-1742.

32. Fukui M, Tanaka M, Shiraishi E, et al. Serum uric acid is associated with microalbuminuria and subclinical atherosclerosis in men with type 2 diabetes mellitus. Metabolism. 2008;57(5):625-629.

33. http://www.fda.gov/... /AdvisoryCommittees/CommitteesMeetingMaterials/... /EndocrinologicandMetabolicDrugsAdvisoryCommittee/ UCM262990.pdf. FDA briefing document. NDA 202293. Dapagliflozin tablets, 5 and $10 \mathrm{mg}$. Sponsor: Bristol-Myers Squibb. Advisory Committee Meeting, July 19, 2011. Washington, DC: Food and Drug Administration. Available from: http://www.fda.gov. Accessed March 26, 2012.

34. DeFronzo RA. Pharmacologic therapy for type 2 diabetes mellitus. Ann Intern Med. 1999;131(4):281-303.

35. Wright EM. Renal $\mathrm{Na}(+)$-glucose cotransporters. Am J Physiol Renal Physiol. 2001;280(1):F10-F18.
Core Evidence

\section{Publish your work in this journal}

Core Evidence is an international, peer-reviewed open-access journal evaluating the evidence underlying the potential place in therapy of drugs throughout their development lifecycle from preclinical to postlaunch. The focus of each review is to evaluate the case for a new drug or class in outcome terms in specific indications and patient groups.

\section{Dovepress}

The manuscript management system is completely online and includes a very quick and fair peer-review system, which is all easy to use. Visit http://www.dovepress.com/testimonials.php to read real quotes from published authors. 